\title{
Quality of sleep in pregnant woman with low back pain
}

\section{Qualidade do sono em gestantes com dor lombar}

\section{Vanessa Patrícia Soares de Sousa, Silvia Oliveira Ribeiro, Carla Monique Ribeiro de Aquino, Elizabel de Souza Ramalho Viana*}

Universidade Federal do Rio Grande do Norte (UFRN), Natal, RN, Brazil

\begin{abstract}
Introduction: Pregnancy is characterized by several changes in her body. These changes contribute to the emergence of low back pain, which may influence the quality of sleep during pregnancy. Objective: To compare the quality of sleep among pregnant women with and without low back pain during pregnancy, examining the relationship between two variables. Materials methods: Thirty volunteers aged between 19 and 36 years, divided into control group (CG - n = 16) and Study Group ( $S G-n=14$ ), residents in the cities of Natal, were evaluated in the second trimester of pregnancy. To sleep evaluation were used to index the Pittsburgh Sleep Quality and the Epworth Sleepiness Scale. Low back pain was evaluated using the pressure algometer, Visual Analogue Scale (VAS) and Oswestry Disability Index. Statistical analysis used the Shapiro Wilk test, Student's T test for independent samples and Pearson correlation test. Results: The mean gestational and chronological ages were $28.2 \pm 3.4$ years and $19.9 \pm 3.7$ weeks, respectively. Sleep quality was lower in SG (8.21 \pm 4.8$)$ when compared to CG $(5.94 \pm 1.7)$ and was statistically significant $(P=0.021)$. Analyzing the relationship between sleep quality and pain intensity, it was observed that the variables have a positive correlation between them
\end{abstract}

\footnotetext{
* VPSS: MSc, e-mail: vanessafisio@gmail.com SOR: undergraduate student, e-mail: silvinha893@hotmail.com CMRA: undergraduate student, e-mail: carlinha_nick@hotmail.com ESRV: PhD, e-mail: elizabelviana@gmail.com
} 
$(\mathrm{r}=0.372, P=0.043)$. Conclusion: Our findings indicate that sleep quality is decreased in women with low back pain compared to those without pain.

Keywords: Pregnancy. Sleep. Low back pain.

\section{Resumo}

Introdução: A gravidez caracteriza-se por diversas mudanças no corpo da mulher. Essas alterações contribuem para o surgimento da dor lombar, que pode influenciar a qualidade do sono durante a gestação. Objetivo: Comparar a qualidade do sono entre mulheres grávidas com e sem dor lombar gestacional, analisando a relação entre as duas variáveis. Materiais e métodos: Trinta voluntárias com faixa etária entre 19 e 36 anos, divididas em grupo controle (GC, sem lombalgia $-n=16$ ) e grupo de estudo (GE, lombalgia $-n=14)$, residentes nos municípios da Grande Natal, foram avaliadas no segundo trimestre de gestação. Para a avaliação do sono foram utilizados o Índice de Qualidade do Sono de Pittsburgh e a Escala de Sonolência de Epworth. A dor lombar foi avaliada utilizando-se o algômetro de pressão, a Escala Visual Analógica (EVA) e o Oswestry Disability Index. Na análise estatística, utilizou-se o teste de Shapiro Wilk, Teste T de Student para amostras independentes e o teste de correlação de Pearson. Resultados: A média das idades cronológica e gestacional foram 28,2 $\pm 3,4$ e 19,9 $\pm 3,7$ semanas, respectivamente. A qualidade do sono foi menor no GE $(8,21 \pm 4,8)$ quando comparado ao GC $(5,94 \pm$ $1,7)$, sendo estatisticamente significativa $(P=0,021)$. Analisando-se a relação entre qualidade do sono e intensidade dolorosa, observou-se que as variáveis apresentam uma correlação positiva entre si $(r=0,372 ; P=0,043)$. Conclusão: Os achados deste estudo indicam que a qualidade do sono encontra-se diminuída em gestantes com lombalgia quando comparadas àquelas sem dor lombar.

Palavras-chave: Gestação. Sono. Lombalgia.

\section{Introduction}

During pregnancy, the woman's body passes through several hormones and biomechanics adjustments (1). These adjustments result in changes in body systems, which allow a normal and secure fetus development (2). The increase in body weight of pregnant women, changes in center of gravity and joint stability, as well as changes in the musculoskeletal alignment, results in painful symptoms and also influences the quality of sleep during pregnancy (3).

Sleep is a highly structured and well-organized activity, which follows a circadian rhythm and it is regulated by the interaction between biological and environmental factors. This process is divided into: a) non-REM (rapid eye movement) sleep that involves a progressive decrease in muscle tone, brain inactivity and on regulation of body activity and b) REM sleep, at which occur the rapid eye movements and it is $20 \%$ of total sleep cycle, which is 90 minutes. Currently, the control of the sleep-wake cycle is attributed to hypothalamic systems and their functional interactions with the timer system circadiano (4).
According to Moldofsky (5), sleep disorders and pain are one of the most common complaints in society and the two conditions are present in the same individual often. Therefore, it is suggested that the pain can cause sleep disturbances, mood impact and greater energy expenditure as well as body behavioural changes.

Investigations have been conducted with the aim of evaluating the relationship between low back pain and the characteristics of the sleep-wake cycle, comparing healthy subjects and low back pain $(5,6,7)$. The results of these studies suggest that there is a relationship between pain symptoms and sleep, considering that individuals with low back pain have a worse quality of sleep compared to healthy people. However, there are few studies about the relationship between low back pain and sleep disorders in populations of pregnant women. In research conducted with 192 pregnant women, Suzuki etal. (8) observed that pain at the lower back and at the hips, in association with fetal movements, interfere on sleep and reduce the alertness during daytime.

Thus, it is emphasized that low back pain during pregnancy is a common, serious and disabling 
symptom (9), especially during the third trimester (10), and the probable causes of this symptom are: the increasing weight of the uterus leading to lumbar hyperlordosis, changes on the center of gravity and posture, laxity of the muscles and hormonal, mechanical and vascular changes (11). Previous studies have shown that low back pain is present in $50 \%$ to $70 \%$ of pregnant women and may have major impact on the mother's life, causing motor disability, insomnia and depression $(1,12)$.

Sleep disorders are also prevalent in pregnant women. However, these were considered normal characteristics of pregnancy, so they are not the target of evaluation and/or treatment by health professionals (13). Among the main sleep disorders, which are characteristics of pregnancy period, those are included: changes in the architecture and sleep patterns, insomnia, excessive daytime sleepiness, respiratory disorders and restless legs syndrome (14). Research analyzing the characteristics of the sleep-wake cycle, during pregnancy, suggest that there is a decrease in the average duration and quality of sleep with the progression of pregnancy $(15,16)$ which, in turn, can influence the type of delivery, duration of parturition (17) and emergence of post partum depression (18).

For this reason, it is relevant to investigate the quality of sleep in pregnant women with and without low back pain, by analyzing the existence of a relationship between pain symptoms and the quality of sleep during pregnancy. In this study, we investigated pregnant women who were in the second trimester of pregnancy. It was adopted as initial hypothesis that pregnant women with low back pain present a poorer quality of sleep, possibly related to pain intensity when compared to those without pain.

\section{Materials and methods}

The research was an observational, analytical, cross-controlled study. It was developed at the Laboratory of Maternal and Child Care Department of Physical Therapy, Federal University of Rio Grande do Norte, from December 2010 to October 2011. This research was submitted to the Ethics Committee for Research on Human Beings of the Federal University of Rio Grande do Norte and approved under protocol number 206/10. The participants signed a Free and Informed Consent Agreement called Termo de
Consentimento livre e esclarecido (TCLE) according to the governing Resolution 196/96 of the National Health Council, and the volunteers who wished to leave the study could do so at any time.

The sample was taken from a population of pregnant women living in Natal - Rio Grande do Norte, Brazil. It was a result of a Non-probabilistic sampling process, consisted of 30 pregnant women. The participants were recruited from public and private care services to pregnant women.

Selection of the volunteers and groups distribution

Were selected for this study, pregnant women who met the inclusion criteria: nulliparous or multiparous, aged between 19 and 36, in the second trimester of pregnancy, which did not present risk of miscarriage, twin pregnancy, severe Pregnancy-Induced Hypertension (PIH), gravidic amendments such as toxemia of pregnancy, severe anemia, placenta previa, gestational diabetes, sleep disorders before pregnancy, do not use medication that affected sleep and did not present difficulty in communication. Those who were excluded during the evaluation period did so by deciding not to continue the research or having gestational complications.

The formation of the study and control groups was based on the presence or absence of one of the studied factor: low back pain. Pregnant women who reported pain symptoms were assigned to the study group ( $S G, n=14$ ), while those without this complaint formed the control group ( $C G, n=16)$.

\section{Clinical and obstetric evaluation}

In order to collect data identification, obstetric history, anthropometric measures and the information related to the participant's living habits, it was used an evaluation sheet previously prepared by researchers.

\section{Sleep evaluation}

The evaluation of the sleep pattern of the participants before pregnancy was performed by a previously structured questionnaire with questions about the amount of hours slept per night, mean time between bedtime and fall asleep, occurrence 
of awakenings throughout the night, degree of difficulty falling back to sleep and comparison of sleep quality before and after pregnancy. These questions were designed based on the work of Neau et al. (14).

Sleep quality was assessed using the Index of Pittsburgh Sleep Quality Index (PSQI), containing 19 questions, divided into 7 areas scored separately. The sum of these scores (range: $0-21$ ) provides a global measure of sleep quality, with high scores indicating insufficient sleep ( $>5$ is indicative of sleep disorders). The domains evaluate multiple components related to the quality of sleep such as: duration, latency, frequency, and severity of specific problems related to sleep as well as impact of poor sleep on the functionality of the body during the day.

The Epworth Sleepiness Scale (ESS) was used to determine the level of daytime sleepiness. The distinction is made between falling asleep and feeling tired. The individual must provide a score from zero to three in 8 different situations, quantifying their tendency to fall asleep in: no chance $=0$; little $=1$; moderate $=2$ and high chance of napping $=3$. The scores range goes from 24 as maximum and minimum of 0 points, with 10 being the normal range.

The Pittsburgh Sleep Quality Index and the Epworth Sleepiness Scale instruments are already validated for the Brazilian population $(19,20)$.

\section{Evaluation of Gestational Low Back Pain (GLBP)}

In order to characterize the intensity of low back pain, it was used Visual Analogue Scale (VAS). This scale is a simple, easy to apply and valid to detect pain intensity. It is scored from 0 (zero) to 10 (ten), where 0 represents no pain and 10 , the maximum supported pain. Pain intensity is divided into categories, where $1-2$ is considered mild; 3 to 7 , moderate; 8 to 9 , intense and 10 is unbearable. This instrument has been widely used for evaluating pain intensity in a population of pregnant women $(12,21)$.

The disability caused by low back pain, the various aspects of the mother's life was assessed using the Oswestry Disability Index. This instrument, self applicable and validated for the Brazilian population by Vigatto et al. (22), contains 10 domains: pain intensity, personal care, weight, walking, sitting, standing, sleeping, sex life, social life and travel. Each domain contains six statements that are scored from 0 (minimum degree of difficulty in the activity) to 5 (highest degree of difficulty). The total score is converted to percentage in which $0-20 \%$ indicates minimal disability, 21-40\% moderate disability, 41$60 \%$ severe disability, $61-80 \%$ poor and $81-100 \%$ total disability.

To evaluate the pain threshold in the lower back, we used the pressure algometer (Pain Diagnostics and Thermography, Great Neck, NY, USA). This device consists of a measuring sphere from 0 to $10 \mathrm{kgf}$ that is capable of measure the force applied through a cylindrical rubber end with $1 \mathrm{~cm}$ of diameter. The pressure was applied at a constant rate until the pressure level at which the stimulus was perceived as pain (pain threshold). The reliability of the algometer has been tested in various studies, it was shown that the it does the quantification of the pain pressure threshold (PPT) during both evaluation and measurements of the treatment program effectiveness for patients with pain $(23,24,25)$. At the moment of evaluation, it was requested that the pregnant woman sit her face turned to the back of the chair and abducted lower limbs, making a slight flexion of the trunk.

The algometry was performed bilaterally at the level of L3, delimiting a lateral distance of $5 \mathrm{~cm}$ from this vertebra, based on the study of Hirayama et al. (26). Three measurements were performed with $30 \mathrm{sec}-$ onds break between them, calculating later the average of the values obtained. Explanations of what the device is and its function were given to pregnant women, and she was instructed to say the word "PAIN" when the stimulus passed from pressure to painful, and then the values obtained in kgf were recorded.

\section{Data analysis}

The statistical analysis was accomplished through the software Statistical Package for the Social Sciences (SPSS) (version 17.0). It was conducted a descriptive statistics via measurements of central tendency (mean), dispersion (standard deviation), absolute and relative values.

To test the normality of the quantitative variables the Shapiro-Wilk test was applied.

In order to compare the frequency of obstetric and anthropometric characteristics, besides attesting to the homogeneity between the groups, the chi-square test was applied. 
The Student's T-test was used for independent samples in order to compare the averages related to sleep quality, the level of excessive sleepiness and pain threshold to pressure among the groups.

To analyze the relationship between sleep quality and subjective pain intensity it was used the Pearson correlation test.

G Power (version 3.1.7) was used to calculate the power of the sample, taking into account the expected effect size of $80 \%$. To calculate the following data were selected: alpha as 0.05 , the number of subjects in each group and the mean and standard deviation of the main variable (quality of sleep).

For all analyzes it was adopted a significance level lower then $0.05(\mathrm{P}<0.05)$.

\section{Results}

The total sample was 30 pregnant women divided into two groups: study group (SG) with low back pain ( $\mathrm{n}=14$ ) and control group (CG) who had no back pain $(n=16)$. The mean chronological and gestational age of the volunteers was, respectively, 28.2 years $( \pm 3.4)$ and $19.9( \pm 3.7)$ gestational weeks. Data for sociodemographic, obstetric and anthropometric characteristics are shown in Table 1.

When compared sleep quality between groups, it was observed that pregnant women with back pain showed a worse quality of sleep, compared to those without pain, with a statistically significant difference presented ( $\mathrm{P}=0.021)$. Regarding the level of daytime sleepiness, there was no significant difference between the groups $(\mathrm{P}=0.732)$. The descriptive results of the evaluation of sleep, according to the Pittsburgh Sleep Quality Index and the Epworth Sleepiness Scale are shown in Table 2

Pain intensity of SG participants $(\mathrm{n}=14)$, measured by VAS, was presented mild to $50 \%$ and moderate for the other $50 \%$. In respect to the interference of low back pain on the activities of the volunteers, we observed the following behaviour: $78.5 \%(n=11)$ from the SG had minimal disability and $21.5 \%(\mathrm{n}=3)$, moderate disability. The evaluation of the painful pressure threshold (PPT) showed that the SG had greater sensitivity bilaterally compared to the CG. However, this difference was not statistically significant $(\mathrm{P}=0.804)$. The data for the algometry groups of pregnant women are shown in Table 3.
Table 1 - Sociodemographic and obstetric characteristics of the sample

\begin{tabular}{lcc}
\hline & \multicolumn{2}{c}{$\begin{array}{c}\text { Sample } \\
(\mathbf{n}=\mathbf{3 0})\end{array}$} \\
\cline { 2 - 3 } Variables & $\mathbf{n}$ & $\%$ \\
\hline Marital Status & 3 & 10 \\
Single & 24 & 80 \\
Married & 3 & 10 \\
Stable Union & & \\
Level of education & 4 & 13.3 \\
High education & 26 & 86.7 \\
Higher education & & \\
Parity & 28 & 93.3 \\
Nulliparous & 2 & 6.7 \\
Multiparous & & \\
\hline
\end{tabular}

Table 2 - Sleep quality comparison and the occurrence of excessive daytime sleepiness between the control group (CG) and study group (SG)

\begin{tabular}{lccc}
\hline \multicolumn{1}{c}{ Variables } & CG $(\mathbf{n}=\mathbf{1 6})$ & SG $(\mathbf{n}=14)$ & $\mathbf{P}$ \\
\hline PSQI & & & \\
& $5.94 \pm 1.7$ & $8.21 \pm 4.8$ & $0.021^{*}$ \\
Bad sleep & $56.3 \%$ & $57.1 \%$ & \\
Good sleep & $43.8 \%$ & $42.9 \%$ & \\
\hline ESS & & & \\
& $9.8 \pm 39$ & $10.14 \pm 3.8$ & 0.732 \\
Fatigue & $62.5 \%$ & $50 \%$ & \\
EDS & $37.5 \%$ & $50 \%$ & \\
\hline
\end{tabular}

Note: $\mathrm{CG}=$ control group; $\mathrm{SG}=$ study group; $\mathrm{PSQI}=$ Pittsburgh Sleep Quality Index; ESS $=$ Epworth Sleepiness Scale; EDS = Excessive daytime sleepiness. ${ }^{*} P<0.05$.

Table 3 - Comparison of painful pressure threshold between groups and body sides evaluation

\begin{tabular}{lccc}
\hline & CG $(n=16)$ & SG $(n=14)$ & P \\
\hline PPT R & $2.6 \pm 1.3$ & $2.2 \pm 1.3$ & 0.804 \\
PPT L & $2.5 \pm 1.1$ & $1.9 \pm 1.3$ & 0.379 \\
\hline
\end{tabular}

Note: $\mathrm{CG}=$ Control Group; $\mathrm{SG}=$ Study Group; PPT = Painful pressure threshold; $\mathrm{R}=$ right side; $\mathrm{L}=$ left side. 
When analyzing the relationship between sleep and pain after applying the Pearson test, it was observed a weak and positive correlation between the variables $(\mathrm{r}=0.372, \mathrm{P}=0.043)$. This correlation is shown in Figure 1.

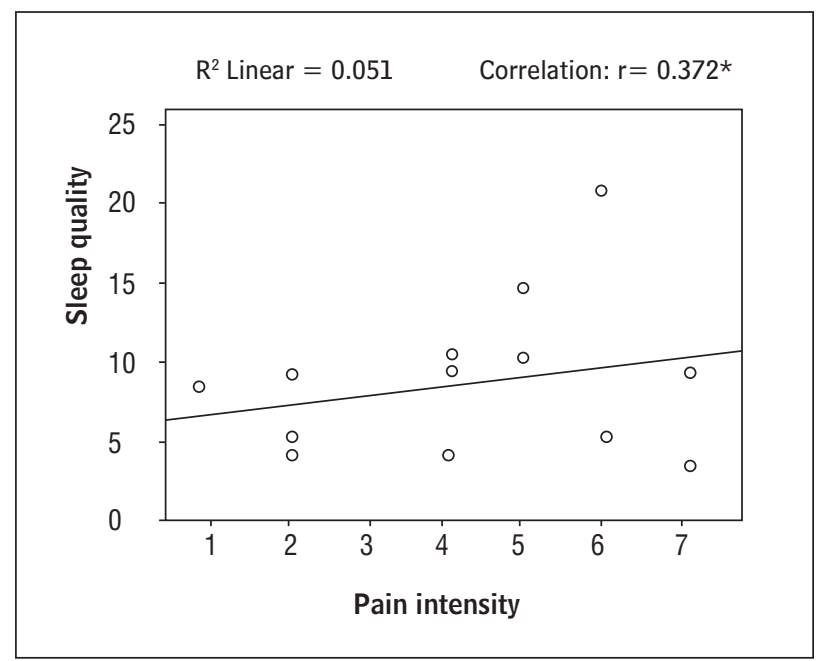

Figure 1 - Correlation between pain intensity and sleep quality $(r=0.372 ; P=0.043)$

Note $={ }^{\star}$ Statistically significant $(P<0.05)$.

To calculate the power of the sample, sleep quality was taken as the main variable, which yield a power of $77 \%$.

\section{Discussion}

The pattern and quality of sleep can be affected by changes related to pregnancy. However, there is not enough research analyzing the relationship between low back pain and sleep during pregnancy or comparing sleep quality between women with and without gestational back pain.

The results of this study showed that women in the second trimester of pregnancy complaining of low back pain have a poorer quality of sleep than those without pain. Gestational low back pain is the result of biomechanical changes imposed by pregnancy period in addition to hormonal changes. The increase of the uterus size leads to the maximum stretching of the abdominal muscles leading to a negative tensionlength relationship this muscle group, which temporarily loses its ability to maintain the posture and therefore the spine stability. Furthermore, the change in center of gravity results in an anterior body imbalance, leading the woman to generate a posteriorization of the upper trunk as a consequence, increases the lumbar lordosis. Therefore, this muscle imbalance increases the tension on the lumbar paraspinal muscles, resulting in pain (27).

The physiological mechanisms that explain the relationship between sleep disorders and chronic pain remain unclear. However, studies indicate that changes in nociceptive processing can cause sleep disturbances. The results of this study corroborate the findings of Marty et al. (7). These authors conducted research with 198 volunteers, 101 patients with chronic low back pain and 97 healthy matched according to sex and age. They found that sleep quality, assessed by the PSQI, was worse in individuals with low back pain compared to healthy subjects. However, the study cited was not conducted with pregnant women, emphasizing thereby the need for research on this topic, considering this specific population.

With respect to the level of daytime sleepiness, the data obtained in this study showed that SG had excessive daytime sleepiness when compared to CG. However, the difference between groups was not statistically significant, suggesting that low back pain does not influence the level of daytime sleepiness during the second trimester. The high average scores of the ESS can be explained by the fact that the second trimester is characterized by episodes of insomnia and therefore the occurrence of non-restorative sleep which may cause excessive daytime sleepiness, regardless of the presence or absence of pain low back pain (28).

The evaluation of pain intensity showed that the most frequent categories were mild to moderate. With respect to the disability caused by lower back pain, most pregnant women had minimal disability. These results corroborate previous study involving 313 pregnant women, which compared pain intensity, the level of disability and the general health of pregnant women with pelvic pain, back pain and the association of the two conditions. The authors found that mild pain intensity and minimum degree of disability in those women with low back pain compared to two groups of volunteers who had severe pain and severe disability (29).

The data obtained in algometry in this study showed that the painful pressure threshold (PPT) was lower in SG bilaterally when compared to the CG, although this difference was not statistically significant. The absence of statistically significant differences 
between groups can be explained by the fact that the pain is the result of a complex interaction between the signalling systems and modulation of higher centers, associated with individual perception (30).

Regarding the lateral pressure of pain perception, the left side showed lower TPP compared to the right side in both groups. This finding may be explained by the fact that the right brain hemisphere is more involved in pain processing, when compared to the left. The cerebral hemispheres present asymmetry on the functioning of the autonomic nervous system. The right hemisphere controls the sympathetic nervous system (SNS), thus, this is stimulated by the left side of the body preferably (31).

When analyzing the relationship between sleep quality and pain scores, the results have shown a direct correlation, statistically significant between the two conditions. These data demonstrate that the more intense back pain, worse sleep quality in women in the second trimester. The increase in pain intensity leads to greater release of inflammatory mediators that stimulate free nerve endings (30), which results in a state of hypervigilance that is characteristic of pain. Thus, the quality of sleep may be affected because, unlike pain, sleep is characterized by a reduced state of vigilance (4). These findings are corroborated by data Marin et al. (6) who conducted research with 268 patients aimed at analyzing the relationship between sleep disorders and chronic low back pain. They obtained direct correlation between sleep quality, measured by the PSQI and pain intensity measured by VAS.

This study highlights the importance of evaluation and analysis of the pain, as well as the sleep quality presented by pregnant women. The data obtained here show that the sleep quality is worse in women with back pain than in pregnant without pain during the second trimester of pregnancy. Furthermore, the intensity of low back pain was directly related to the quality of sleep. However, algic condition did not influence the level of daytime sleepiness, pain threshold to pressure and functionality of the woman's body. These results emphasize two important changes that may occur during the pregnancy period and that should be the target of attention from health professionals: low back pain and sleep quality in association with its influence on activities of daily life of the pregnant woman. It also should be noted that preventive measures or early interventions for the management of low back pain can provide a better quality of sleep during pregnancy.
It is suggested then that other research related to this topic is conducted, considering a larger sample size and also assessments on the first and third trimesters of pregnancy.

\section{Acknowledgement}

The Women's Health Study Group on Physiotherapy at the Universidade Federal do Rio Grande do Norte (GEMS/UFRN) thanks the Coordenação de Aperfeiçoamento de Pessoal de Nível Superior (CAPES) for the financial support, which enabled this research.

\section{References}

1. Novaes FS, Shimo AKK, Lopes MHBM. Low back pain during gestacion. Rev Latino-Am Enfermagem. 2006;14(4):620-4.

2. Nagai M, Isida M, Saitoh J, Hiara Y, Natori H, Wada N. Characteristics of the control of standing posture during preganancy. Neurosci Lett. 2009;462(2):130-4.

3. Gilleard W, Lai DTH, Begg RK. Detection trunk motion changes due to pregnancy using pattern recognition techniques. In: Proceedings of the 30th Annual Internacional Conference IEEE EMBS; 2008 Aug 20-24; Vancouver, Canada, August 20-24. Piscataway: EMBS Executive Office; 2008.

4. Valenza MC, Rondestein D, Fernández-de-las-Peñas C. Consideration of sleep dysfunction in rehabilitation. J Bodyw Mov Ther. 2011;15(3):262-7.

5. Moldofsky H. Sleep and pain. Sleep Med Rev. 2001;5(5):385-96.

6. Marin R, Cyhan T, Miklos W. Sleep disturbance in patients with chronic low back pain. Am J Phys Med Rehabil. 2006;85(5):430-5.

7. Marty M, Rozenberg S, Duplan B, Thomas B, Duquesnay B, Allert F. Quality of sleep in patients with chronic low back pain: a case-control study. Eur Spine J. 2008;17(6):839-44.

8. Suzuki S, Dennerstein L, Greenwood KM, Armstrong SM, Satohisa E. Sleeping patterns during pregnancy in Japanese women. J Psychosom Obstet Gynaecol. 1994;15(1):19-26. 
9. Wu W, Meijer OG, Jutte PC, Uegaki K, Lamoth CJC, Wolf GS, et al. Gait patient with pregnancy-related pain in the pelvis: an emphasis on the coordination of transverse pelvic and thoracic rotations. Clin Biomech. 2002;17(9-10):678-86.

10. Pitangui ACR, Ferreira CHJ. Avaliação fisioterapêutica e tratamento da lombalgia gestacional. Fisioter Mov. 2008;21(2):135-42.

11. Setse R, Grogan R, Pham L, Cooper LA, Strobino D, Powe $\mathrm{NR}$, et al. Longitudinal study of depressive symptoms and health-related quality of life during pregnancy and after delivery: the health status in pregnancy (HIP) study. Matern Child Health J. 2009;13(5):577-87.

12. Martins RF, Pinto e Silva JL. Prevalência de dores nas costas na gestação. Rev Assoc Med Bras. 2005;51(3):144-7.

13. Sloan EP. Sleep disruption during pregnancy. Sleep Med Clin. 2008;3(1):73-80.

14. Neau JP, Teixer B, Ingrand P. Sleep and vigilance disorders in pregnancy. Eur Neurol. 2009; 62(1):23-9.

15. Facco FL, Kramer J, Ho KH, Zee PC, Grobman WA. Sleep disturbances in pregnancy. Obstet Gynecol. 2010;115(1):77-83.

16. Borodulin K, Evenson KR, Monda K, Wen F, Herring AH, Dole N. Physical activity and sleep among pregnant women. Paediatric Perinat Epidemiol. 2010;24(1):45-52.

17. Lee KA, Gay CL. Sleep in late pregnancy predicts length of labor and type of delivery. Am J Obstet Gynecol. 2004;191(6):2041-6.

18. Okun ML, Roberts JM, Marsland AL, Hall M. How disturbed sleep may be a risk factor for adverse pregnancy outcomes. Obstet Gynecol Surv. 2009;64(4):273-80.

19. Bertolazi AN, Fagondes SC, Perin C, Schonwald SV, John AB, Miozzo ICS. Validation of the Pittsburgh Sleep Quality Index in the Brazilian portuguese language. In: Proceedings of the 22nd Annual meeting of the associated professional sleep societies; 2008; Baltimore. Westchester: APSS; 2008. p. a347.

20. Bertolazi AN, Barreto SSM, Drehmer M. Tradução, adaptação cultural e validação da Escala de Sonolência de Epworth. In: Anais do 33. Congresso Brasileiro de Pneumologia e Tisiologia; 2006; Fortaleza. São Paulo: Jornal Brasileiro de Pneumologia; 2006. p. 217-402.

21. Martins RF, Pinto e Silva JL. Tratamento da lombalgia e dor pélvica posterior na gestação por um método de exercícios. Rev Bras Ginecol Obstet. 2005;27(5):275-82.
22. Vigatto R, Alexandre NM, Correa Filho HR. Development of a Brazilian Portuguese version of the Oswestry Disability Index: cross-cultural adaptation, reliability, and validity. Spine. 2007;32(4):481-6.

23. Antonaci F, Sand T, Lucas GA. Pressure algometry in healthy subjects: inter-examiner variability. Scand J Rehabil Med. 1998;30(1):3-8.

24. Lima ICM, Seguchi HHK, Imamura M. Tratamento da lombalgia crônica pela inativação de pontos-gatilho miofasciais: experiência da Divisão de Medicina Física da FMUSP. Acta Fisiátr. 1999;6(1):10-3.

25. Potter L, McCarthy C, Oldham J. Algometer reliability in measuring pain pressure threshold over normal spinal muscles to allow quantification of anti-nociceptive treatment effects. Int J Osteopath Med. 2006;9(4):113-9.

26. Hirayama J, Yamagata M, Ogata S, Shimizu K, Ikeda Y, Takahashi K. Relationship between low-back pain, muscle spasm and pressure pain thresholds in patients with lumbar disc herniation. Eur Spine J. 2006;15(1):41-7.

27. Sabino J, Grauer JN. Pregnancy and low back pain. Curr Rev Musculoskelet Med. 2008;1(2):137-41.

28. Pires GN, Andersen ML, Giovenardi M, Tufik S. Sleep impairment during pregnancy: possible implications on mother-infant relationship. Med Hypotheses. 2010;75(6):578-82.

29. Gutke A, Ostegaard HC, Oberg B. Pelvic girdle pain and lumbar pain in pregnancy: a cohort study of the consequences in terms of health and functioning. Spine. 2006;31(5):E149-55.

30. Steeds CE. The anatomy and physiology of pain. Surgery. 2009;27(12):507-11.

31. 31-Wasan AD, Anderson NK, Giddon DB. Differences in pain, psychological symptoms, and gender distribution among patients with left- vs right-sided chronic spinal pain. Pain Med. 2010;11(9):1373-80.

Received: 07/27/2012 Recebido: 27/07/2012

Approved: 02/26/2015 Aprovado: 26/02/2015 